\title{
TO STUDY THE EFFICACY OF LOOP ELECTROSURGICAL EXCISIONAL PROCEDURE (LEEP) IN THE MANAGEMENT OF PRECANCEROUS CERVICAL LESIONS IN LOW RESOURCE SETTINGS
}

\author{
Sapna Singh', Pavika Lal², Sanjay Nigam³, Anju Gahlot ${ }^{4}$ \\ ${ }_{1}^{1}$ Associate Professor, Department of Obstetrics and Gynaecology, Rama Medical College Hospital \& Research Centre, Kanpur. \\ ${ }_{2}^{2}$ Assistant Professor, Department of Obstetrics and Gynaecology, Rama Medical College Hospital \& Research Centre, Kanpur. \\ 3 Professor, Department of Pathology, Rama Medical College Hospital \& Research Centre, Kanpur. \\ 4 Professor, Department of SPM, Rama Medical College Hospital \& Research Centre, Kanpur.
}

ABSTRACT
BACKGROUND
Large Loop Excision of the Transformation Zone (LLETZ) is a simple outpatient excisional procedure for transformation zone (TZ)
of the cervix. Carcinoma in situ is the forerunner of invasive carcinoma of the cervix. Process of carcinogenesis starts at the
transformation zone (TZ). LEEP is used for management of cervical intraepithelial neoplasia (CIN). It is a diagnostic and
therapeutic procedure.
Objective- To study the efficacy of LEEP in the management of precancerous cervical lesions in low resource settings.

\section{MATERIALS \& METHODS}

This study was done by performing Liquid Based Cytology (LBC) on 483 patients who attended the OPD of Obstetrics \& Gynaecology Department in Rama Medical College, out of which 58 patients who had precancerous lesions on LBC underwent LEEP.

\section{RESULTS}

The incidence of pre-invasive cervical lesions in our study was $12 \%$. The mean duration of the surgical procedure was $15 \pm 3$ minutes. The only significant early post-surgical complication was bleeding which occurred in 2 patients. There were significant changes in the histopathological findings after LEEP.

\section{CONCLUSION}

LEEP is proved to be an effective management for the treatment of precancerous cervical lesions at our setting with minimal complications needing little training skills.

\section{KEYWORDS}

Cervical Cancer, LEEP (Loop Electrosurgical Excisional Procedure), Premalignant Lesions, Transformation Zone (TZ), Liquid Based Cytology (LBC).

HOW TO CITE THIS ARTICLE: Singh S, Lal P, Nigam S, et al. To study the efficacy of loop electrosurgical excisional procedure (LEEP) in the management of precancerous cervical lesions in low resource settings. J. Evolution Med. Dent. Sci. 2017;6(14):10991102, DOI: $10.14260 /$ Jemds/2017/238

\section{BACKGROUND}

Cervical cancer is the commonest cancer cause of death among women with $86 \%$ of all the cervical cancer deaths occurring in developing countries.(1,2,3) Every year in India, 122,844 females are diagnosed with cervical cancer and 67,477 die from the disease.(4)

It is the second most common cancer in women aged 1544 Years. ${ }^{(4)}$

The unique accessibility of the cervix to direct visual inspection \& the longstanding nature of the premalignant lesions of cervix make carcinoma cervix a preventable disease. Several screening programs have been developed

Financial or Other, Competing Interest: None.

Submission 10-01-2017, Peer Review 03-02-2017,

Acceptance 09-02-2017, Published 16-02-2017.

Corresponding Author:

Dr. Sapna Singh,

Flat No. 203,

Staff Accomodation-1,

RMC Campus, Mandhana,

Kanpur.

E-mail: sapnasingh.305@gmail.com

DOI: $10.14260 /$ jemds $/ 2017 / 238$

\section{(c) $(1)(5)$}

that aim at detection of precancerous cervical lesions along with institution of effective treatment.

Various modalities of treatment have been evolved for regression of premalignant lesions. Ablative methods like cryotherapy, electrocautery, cold coagulation and electrocoagulation diathermy rely on accurate colposcopically directed biopsy diagnosis, because no tissue is available for histopathological confirmation \& therefore are only therapeutic. On the other hand, excisional procedures like LEEP and Cone Biopsy are both diagnostic \& therapeutic. LEEP [also known as large loop excision of the transformation zone (LLETZ)], utilises a thin electric wire to remove the entire transformation zone of the cervix.

A loop is a very thin stainless steel wire of 2-3 cm used for excision of transformation zone with blended current, (cutting \& coagulation) with low voltage output is used, tissue up to the depth of $10 \mathrm{~mm}$ or more can be removed. Lesion must be localised by colposcopy and an appropriate size of loop should be selected. If ectocervical margin of excision is positive, repeat excision can be performed easily. If endocervical margin is positive for CIN, followup with cytology using Cytobrush or endocervical curettage is required. 
The present study aimed to evaluate the effectiveness of LEEP in treatment of various degrees of cervical dysplasias.

\section{MATERIALS \& METHODS}

This was a prospective study conducted at the Department of Obstetrics and Gynaecology at Rama Medical College and Research Centre, Mandhana, Kanpur from September 2014 to March 2016. Total number of subjects included in the study were 58 out of 483 attending the OPD, who presented with one or more of following complaints of unhealthy discharge, intermenstrual or postcoital bleeding along with unhealthy or hypertrophied cervix on per-speculum examination. Exclusion criteria were pregnant females, age $>65$ or $<18$ years, unmarried females, and females who have had hysterectomy or did not give consent for the study. All 483 cases were screened for dysplasia using Liquid Based Cytology out of which 58 cases were selected for colposcopic examination on the basis of cervical cytology with CIN II in 23 patients, CIN III 14 patients and persistent CIN-I in 21 patients (even after 1 year of followup) (Table 1). Colposcopic grading was done using the newly introduced Swede score. Strander et al has devised a new scoring system, the Swede score, which includes lesion size as a variable. Swede Score of 8 or more had a sensitivity, specificity, positive and negative predictive values of 38\%, 95\%, $83 \%$ and $70 \%$ respectively for lesions where the final diagnosis was CIN II or higher.[5] The Swede score evaluation of scoring system was designed to improve the predictive value of colposcopy. All 58 cases were also subjected to human papillomavirus testing \& HIV testing after proper voluntary counselling \& testing.

LEEP was performed under local anaesthesia (Paracervical block), patients were put in dorsal lithotomy position and insulated Cusco's speculum was used to spread apart the vaginal wall for proper visualisation of the cervix. Colposcopy was used to magnify the cervix during the surgery \& tissue sent for histopathological examination. Roller ball was used to achieve haemostasis after the procedure followed by vaginal packing which was removed at the time of discharge. All cases were followed at 3 and 6 months using cytology and colposcopy to detect the presence or absence of residual or recurrent disease.

\section{RESULTS}

The incidence of pre-invasive cervical lesions at our institution was $12 \%$ (58/483), majority of the patients with high grade cervical lesions belong to lower socioeconomic group with higher parity (Table 2). In our study, human immunodeficiency virus (HIV) seropositivity was found in $8.62 \%(5 / 58)$, and HPV positivity was seen in $88 \%(51 / 58)$ of cases especially with high grade lesions. The mean duration of the surgical procedure and hospital stay were $15 \pm 3$ minutes and $12 \pm 4$ hours respectively. This reflects that LEEP is a relatively easier procedure which can be easily skilled by the physicians for the treatment of precancerous cervical lesions. Complete cervical wound healing was achieved in all the patients during the three month followup period. The only significant complication was early post-operative bleeding which was managed conservatively (Table 4).

Post-operative histology of 58 patients who under gone for LEEP revealed that out of 21 patients with CIN I in cytology, only 11 patients had mild dysplasia \& 8 patients had only chronic cervicitis without dysplasia after LEEP. 2 patients of CIN I shifted to CIN II, out of 23 patient of CIN II in cytology, 2 shifted to CIN III and 1 patient of CIN II shifted to microinvasive carcinoma, now 22 patients shows CIN II features. Out of 14 patients of CIN III in cytology, 3 patients shifted to microinvasive stage, now 13 patients show CIN III features and microinvasive carcinoma was present in 4 patients after LEEP (Table 3).

\begin{tabular}{|c|c|c|}
\hline & No. of Pts. & \% \\
\hline Persistent CIN I & 21 & $36.21 \%$ \\
\hline CIN II & 23 & $39.65 \%$ \\
\hline CIN III & 14 & $24.13 \%$ \\
\hline Total & $\mathbf{5 8}$ & $\mathbf{1 0 0 \%}$ \\
\hline $\begin{array}{r}\text { Table 1. Patients According to Distribution of Liquid } \\
\text { Based Cytology CIN treated by LEEP }\end{array}$ \\
\hline
\end{tabular}

This table shows the distribution of patients according to their histological findings of cervical smear by liquid based cytology, out of 58 patients, 21 patients showed persistent CIN I, 23 patients showed CIN II and 14 patients showed CIN III features.

\begin{tabular}{|c|c|c|}
\hline Persistent CIN I & CIN II & CIN III \\
\hline $\mathrm{N}=21$ & $\mathrm{~N}=23$ & $\mathrm{~N}=14$ \\
\hline Table 2. Sociodemographic Profile of the Patients \\
with Pre-Invasive Cervical Precursors
\end{tabular}

\begin{tabular}{|c|c|c|c|}
\hline \multicolumn{4}{|c|}{ Parity } \\
\hline PI & $2(3.44 \%)$ & & \\
\hline P2 & $8(13.79 \%)$ & $13(22.41 \%)$ & $5(8.62 \%)$ \\
\hline$\geq$ P3 & $11(18.96 \%)$ & $10(17.24 \%)$ & $9(15.51 \%)$ \\
\hline \multicolumn{4}{|c|}{ Table A } \\
\hline
\end{tabular}

\begin{tabular}{|c|c|c|c|}
\hline \multicolumn{4}{|c|}{ Age } \\
\hline 20-30 Years & $6(10.34 \%)$ & $5(8.62 \%)$ & \\
\hline 31-40 Years & $12(20.68 \%)$ & $11(18.96 \%)$ & $6(10.34 \%)$ \\
\hline 41-50 Years & $3(5.17 \%)$ & $7(12.06 \%)$ & $8(13.79 \%)$ \\
\hline \multicolumn{4}{|c|}{ Table B } \\
\hline
\end{tabular}

\begin{tabular}{|c|c|c|c|}
\hline \multicolumn{5}{|c|}{ Socioeconomic Status } \\
\hline Lower & $14(24.13 \%)$ & $19(32.75 \%)$ & $10(17.24 \%)$ \\
\hline Middle & $5(8.62 \%)$ & $3(5.17 \%)$ & $4(6.89 \%)$ \\
\hline Upper & $2(3.44 \%)$ & $1(1.72 \%)$ & -- \\
\hline \multicolumn{4}{|c|}{ Table C } \\
\hline
\end{tabular}

\begin{tabular}{|c|c|c|c|}
\hline $\begin{array}{c}\text { HIV } \\
\text { Seropositivity }\end{array}$ & $3(5.17 \%)$ & $2(3.44 \%)$ \\
\hline $\begin{array}{c}\text { HPV } \\
\text { Seropositivity }\end{array}$ & $16(27.58 \%)$ & $21(36.20 \%)$ & $14(24.13 \%)$ \\
\hline \multicolumn{4}{|c|}{ Table D } \\
\hline
\end{tabular}

This Table Shows the Distribution of Patients in Grades of Neoplasia According to their-

A. Parity- Mild dysplasia was present in low parity, high grade dysplasia was seen more in high parity females.

B. Age- Low grade dysplasia was seen more in 20-30 years of age \& high grade dysplasia was seen more in $30-50$ years of age.

C. Socioeconomic Status- High grade dysplasia was more seen in lower socioeconomic status \& low grade dysplasia was more seen in higher socioeconomic status. 
D. HIV \& HPV Seropositivity- 5 patients were found to be HIV positive and 51 patients were HPV Positive.

\begin{tabular}{|c|c|c|}
\hline Grade & $\mathbf{n}$ & $\%$ \\
\hline $\begin{array}{c}\text { Cervicitis without } \\
\text { dysplasia }\end{array}$ & 8 & $13.79 \%$ \\
\hline CIN I & 11 & $18.96 \%$ \\
\hline CIN II & 22 & $37.93 \%$ \\
\hline CIN III & 13 & $22.41 \%$ \\
\hline Micro Invasive Car & 4 & $6.89 \%$ \\
\hline \multicolumn{3}{|c|}{$\begin{array}{c}\text { Table 3. Distribution of Patients with respects to Post- } \\
\text { operative Histology Patient treated by LEEP; N=58 Post- } \\
\text { operative Histology }\end{array}$} \\
\hline
\end{tabular}

This table shows the histological changes in cytology of cervical smear after LEEP, out of 58 patients, 8 patients showed normal cytology with no dysplasia, 11 patients showed CIN I features, 22 patients showed CIN II and 13 patients showed CIN III features, 4 patients were presented with microinvasive carcinoma.

\begin{tabular}{|c|c|c|}
\hline Complications & $\mathbf{N}$ & $\mathbf{\%}$ \\
\hline $\begin{array}{c}\text { Early postop } \\
\text { bleeding }\end{array}$ & 2 & $3.44 \%$ \\
\hline $\begin{array}{c}\text { Pelvic } \\
\text { Inflammatory } \\
\text { disease }\end{array}$ & 1 & $1.72 \%$ \\
\hline Cervical Stenosis & 1 & $1.72 \%$ \\
\hline Residual Disease & Nil & $0 \%$ \\
\hline \multicolumn{2}{|c|}{ Table 4. Complication of LEEP } \\
\hline \multicolumn{2}{|c}{}
\end{tabular}

This table shows the complications of LEEP, most important early post-operative complication was bleeding per vaginum in $3.44 \%$ of patients, PID was seen in $1.72 \%$ and cervical stenosis was seen in $1.72 \%$ of patients.

\section{DISCUSSION}

Majority of the patients who underwent LEEP in our series were in the age group of 30-40 Years (Table 2), which was slightly lower than the other studies, $(5,6,7,8)$ this difference might be due to early age of marriage \& completion of family at an early age in our country, predisposing the patients to development of precancerous cervical lesions at an early age. In our series, majority of the patients belonged to lower socioeconomic group. A meta-analysis of social inequality and the risk of cervical cancer showed a $100 \%$ increased risk in the low social class categories for the development of invasive cervical cancer. ${ }^{(9)}$

Human Papilloma Virus (HPV) prevalence among cervical cancer patients in India has varied from $87.8 \%$ to $96.67 \%$. $(10,11,12,13)$ Our study also showed a strong correlation between HPV seropositivity for 16 \& 18 and pre-invasive cervical lesions in $88 \%$ cases.

HIV infection was seen in $8.62 \%$ of patients in our study. Several studies have found that HIV infected females are at higher risk of cervical precancerous lesions than those without infection with Odds Ratio (OR) in the range of 4.1 to 11. $(14,15)$ Indeed it is thought that the immune impairment due to HIV infection will lead to the persistence of HPV infection which increases the risk of precancerous lesions of the cervix.(16) The mean duration of the surgical procedure in our study was $15 \pm 3$ minutes and the duration of hospital stay was $12 \pm 4$ hours, which was comparatively similar to the study conducted by Ngowa et al.

The study showed that there was change in the severity of dysplasia obtained after LEEP preceded by colposcopy when as compared to cytology alone as 4 patients were identified to have microinvasive carcinoma which was missed by liquid based cytology (LBC) alone. Also 8 were identified to have only chronic cervicitis without any degree of dysplasia after LEEP. Excisional treatment methods such as LEEP have the advantage of providing tissue specimens for histopathological diagnosis thereby reducing the possibility of incomplete eradication of precancerous cells.

The limitation of this study was the small sample size which constitutes a selection bias. However, the merit of this study was to provide an idea about the feasibility of the treatment of CIN by LEEP in low resource settings.

Complication rate in our study was $6.8 \%$ but no residual disease was observed at $3 \& 6$ months followup. The rate of early postoperative bleeding was $3.4 \%$ in our study which was similar to the $4.9 \%$ \& $5.4 \%$ reported by other authors.(17,18)

In developed countries, management of precancerous cervical lesions has shifted from use of inpatient surgical methods to use of outpatient approaches. In developing countries; however, clinicians still opt aggressive approaches such as conization or hysterectomy, therefore LEEP has been introduced as an outpatient procedure which can successfully be done in our settings.

\section{CONCLUSION}

From our study we conclude that LEEP is a simple, feasible \& effective management strategy for treatment of precancerous cervical lesions as it has both diagnostic \& therapeutic importance. It may be considered as a suitable alternative to cold knife conization or hysterectomy for younger females who are yet to complete their families. However, adequate training is essential to ensure proper treatment.

\section{REFERENCES}

[1] Denny L. Cervical cancer: prevention and treatment. Discover Med 2012;14(75):125-31.

[2] Arbyn M, Castellsague X, de Sanjose S, et al. Worldwide burden of cervical cancer in 2008. Ann Oncol 2011;22(12):2615-86.

[3] Yeole BB, Kumar AV, Kurkuveet A, et al. Population based survival from cancers of breast, cervix and ovary in women in Mumbai, India. Asian Pac J Cancer Prev 2004;5(3):308-15.

[4] ICO information centre on HPV \& Cancer (Summary Report 2014-08-22). Human papillomavirus and related diseases in India 2014.

[5] Bowring J, Strander B, Young M, et al. The Swede score: evaluation of a scoring system designed to improve the predictive value of colposcopy. J low genit tract dis 2010;14(4):301-5.

[6] Yomi J, Monkam G, Tagni D, et al. Anatomical-clinical presentation and prognostic factors in cancers of the cervix at the general hospital of Yaoundé. West African Journal of Medicine 1999;18(1):20-3. 
[7] Tebeu PM, Petignat P, Mhawech-Fauceglia P. Gynaecological malignancies in Maroua, Cameroon. International Journal of Gynaecology \& Obstetrics 2009;104(2):148-9.

[8] Ngowa DJK, Anny N, Tsuala FJ, et al. Management of cervical intra epithelial neoplasia by loop electrosurgical excision procedure in a low resource country: an experience from the Yaoundé general hospital, Cameroon. Open Journal of Obstetrics \& Gynaecology 2015;5(9):481-6.

[9] Seema P, Paul B, Boffetta P. Meta-analysis of social inequality and the risk of cervical cancer. Int J Cancer 2003;105(5):687-91.

[10] Sowjanya AP, Jain M, Poli UR, et al. Prevalence and distribution of high risk human papilloma virus (HPV) types in invasive squamous cell carcinoma of the cervix and in normal women in Andhra Pradesh, India. BMC infect Dis 2005;5:116.

[11] Kulkarni SS, Vastrad PP, Kulkarni BB, et al. Prevalence and distribution of high risk human papilloma virus (HPV) types 16 and 18 in carcinoma of cervix, saliva of patients with oral squamous cell carcinoma and in the general population in Karnataka, India. Asian Pac J Cancer Prev 2011;12(3):645-8.

[12] Gheit T, Vaccarella S, Schmitl M, et al. Prevalence of human papilloma virus types in cervical and oral cancers in central India. Vaccine 2009;27(5):636-9.
[13] Basu P, Roychowdhary S, Bafna UD, et al. Human papillomavirus genotype distribution in cervical cancer in India: results from a multi-centre study. Asian Pac J Cancer Prev 2009;10(1):27-34.

[14] Moodley JR, Hoffmann M, Carrara H, et al. HIV and preneoplastic and neoplastic lesions of the cervix in South Africa: a case control study. BMC Cancer 2006;6:135.

[15] Hawes SE, Cathy CW, Faye NMA, et al. Increased risk of high grade cervical squamous intraepithelial lesions and invasive cervical cancer among African women with human immunodeficiency virus type 1 and 2 infection. Journal of infections diseased 2003; 188(4):555-63.

[16] Strickler HD, Burk RD, Fazzari M, et al. Natural history and possible reactivation of human papillomavirus in human immunodeficiency virus positive women. Journal of the National Cancer Institute 2005;97(8):577-86.

[17] Sutthichon P, Kietpeerkool C. Perioperative complications of an outpatient loop electrosurgical excision procedure: a review of 857 consecutive cases. Asian Pacific Journal of Cancer prevention 2009;10(3):351-4.

[18] Panna S, Luanratanakorn S. Positive margin prevalence and risk factors with cervical specimens obtained from loop electrosurgical excision procedures and cold knife conisation. Asian Pacific Journal of Cancer Prevention 2009;10(4):637-40. 